\title{
An Assessment of Institutional Health for Adolescent Girls
}

\author{
Shradha Padhi*, Sucheta Priyabadini and Santosh Kumar Pradhan \\ KIIT University, School of Management, Bhubaneswar - 751024, Odisha, India; shradha_padhi@ksom.ac.in, \\ sucheta@kiit.ac.in, kumarsantoshpuri@gmail.com
}

\begin{abstract}
Objectives: This article is an attempt to understand the impact of quality education of hygienic and sanitation practices among adolescent girls in secondary schools of Bhubaneswar, Odisha on their professional career. Methods/Statistical Analysis: The study is primarily based on exploratory research, observational approach and consultation through field visits during the study process. The authors used semi structured interview schedule for quantitative information. Case studies and Focus Group Discussion tools were applied for qualitative analysis. For the sample, adolescent girl students, studying between standard 8 to 10 , in 10 government secondary schools were selected. Great care was undertaken to draw the sample from similar socio-economic backgrounds. While correlation statistical methods were used for quantitative factors, qualitative factors were evaluated through critical investigations. Findings: The study is purely event based exploratory research and addressing core values at ground zero. The study aims to focus on the understanding of the cultural practice of personal hygiene for adolescent girls and how it is impacting on their career growth from the entry stage. It also tries to examine efficacy of institutional initiatives for providing personal hygiene and sanitation practices at the school level. The initial study suggested that inadequate coping mechanisms and deprivation of basic sanitary facilities hurts self-control, thereby, leading to dropouts from the schools. It was felt that the pro-active role of teachers in counseling and understanding the psychosocial circumstance could play a major role in reduction of innumerable dropouts of adolescent girl students. Provision for sanitary facilities exclusively for girl students, may be low cost, may contribute in retaining girl students. Application/Improvements: The study exploratory research. This is a new insight to practicality, psycho social theory and effective management model. This research paper has relevant implications and concludes with a number of future research ideas.
\end{abstract}

Keywords: Adolescent Girl, Culture, Hygiene, Management Model, Sanitation

\section{Background}

Education through small schools is an age old practice in India, traced back to thousands of years. They were considered not only as one of the important institution for acquiring knowledge, but also promoting the young into a complete human being with good health. Similar situations prevailed all over the world. But institutionalized health promotion programmes have been a recent development across the globe. Most countries in the world are now redesigning and implementing their policies on health awareness and health education focusing on their characteristic socio economic status. Updated course curriculum has played a crucial role to enlighten the students on the importance of health education at the school level. Probably it is the only sector where young generation could access health promotion work and can also transcend to newer generations accordingly $y^{1}$.

In particular; nutrition and health have featured prominently in institutional set up and medical circles. The World Health Organization defined health as a "state of complete physical, mental and social well-being and not merely the absence of disease or infirmity".

India is at pace with the world in providing health education to the young students, having incorporated hygiene as part of the course curriculum and providing healthy lunch to the students.

${ }^{*}$ Author for correspondence 
While healthy free lunch is an attraction for the students, poor sanitary facilities is a distraction for the adolescent girls. A balancing solution needs to be carved out to deal with the situation. This paper is an early attempt and provides prospective researchers myriads of avenues.

In present era school based health promotion has not been demarcated in proper order in our society. But, the basic ingredients those are required for health promotions are being replicated gradually. Meanwhile, the programmes are well planned, implemented and evaluated through considering effectiveness of health situation at the ground level 2.

A new initiative named Whole School Approach was developed in London through collaborative action for promoting health services in the schools at the ground level. Under the scheme, the community people took initiatives for disseminating health awareness for the school going children $\frac{3,4}{4}$. The approach received appreciations across European countries. Basing upon the model, the European Union launched Health Network in schools in 1992. The international organizations like World Health Organization, the Council of Europe and European Commission noticed the effectiveness of the programme implemented in 40 countries across the Europe. In fact, wider acceptance, appropriateness into the reality and sustainability effectiveness were considered and evaluated in a systematic order $\underset{5,6}{ }$.

The scenario in India was different with the absence of partnership approach. Rather the system operated independently within the structural frame work and guideline of the government at the center and state level. However, the schools need to take collaborative approach towards promoting better health and education, particularly for the adolescent girls, as they are prone to be more vulnerable groups. Considering to the needs and importance of health in schools, the priorities were shifted to participatory approach where the community people along with school institutions took responsibility towards delivering health services in selected schools. But, there were some rigid principle involved in selecting the schools for this purpose. Mostly the viability and capacity of the institutions were taken into consideration. However, during 1990s, the government started focusing on formalized process with an intention to work on heath promotion. In 1997, the Department of Education and Employment published a white paper on the basis of excellence of schools with respect to education and health services. The programmes had been specifically focused on the schools as targeting to the young generation and special attention for increasing individual and community level health services would ultimately control on the lives and life style at the institute level. It is considered as one of the most significant and successful programme through innovative approach and partnership efforts of the community people and key personnel of the institute concerned $\frac{6-8}{}$.

The Central government has been focusing on providing better institutional health services through school at the primary level since 1998. International agencies are also involved in monitoring and assisting for the effective implementation of the schemes benefiting the vulnerable section of the society. The objective behind of this project is to create best platform at the ground level where various stake holders operating at community could come forward and share ideas as well as opinion to access institutional health services from the concerned agencies. This might be one of the processes where qualitative health education could be achieved. Qualitative education always follows a dynamic and multi-pronged approach. A conducive atmosphere in social, economic, cultural and environment is highly essential ${ }^{9-11}$.

Adolescence is a critical phase in the lives of human beings with changes occurring both in physical and psychological levels. Adolescent girls are more prone to health complications requiring proper attention and guidance. The school is the proper place where she can be aware and be able to take right care of her health. Attention to health issues would definitely give positive output in other associated fields.

\section{Methodology}

Overall growth and development of adolescent girls normally occurs during the period she attends secondary school. Within institutional structure, an adolescent girl needs to access health and hygiene facilities. The authors decided to explore the facts and ground realty about the situation of adolescent health and hygiene practice in secondary schools. For, this purpose exploratory research method was chosen where observational approach is adopted. In addition to this, Focus Group Discussion, Key Informant Interviews and case studies were used to gather qualitative information.

For the research, 10 government secondary schools were selected, where $8^{\text {th }}, 9^{\text {th }}$ and $10^{\text {th }}$ standard girl students studied. Group discussions were conducted among the 
peer group focusing on critical areas of adolescent girls relating to health, hygiene and education. The teacher's views and school management committee members' opinion were also considered and incorporated while developing health and hygiene model for adolescent school girls. The authors worked on two objectives. First, creating a low cost health and hygiene model for sanitary facilities within educational premises. Second, evaluating the impact of counseling by teachers reaching addressing the psychosocial issues which, in turn, contribute towards reducing girl child drop out during, pre and post menstrual periods in a month.

\section{Adolescent - under Bracket}

The top priority during adolescent stage should be given to productive human growth and development. Still thorough research and investigation is lacking in this field. There are few areas where the adolescent are generally getting confused, like preferable career path and healthy lifestyle. The socio-cultural aspects play a major role in this aspect. Body sensation and unusual feelings during this transition period distract the adolescent's focus away from the career plan and overall development. The mismatch of thought process between the adolescent and persons she interacts create confusions and pose as a major obstacle for the holistic development. It has direct proportional relationship with emotional as well as cognitive aspects. Opposite gender relationship has also significant role to address adolescent health. To overcome such situation, peer group intervention, along with guided supports within formal institutional setup would definitely impact the inner development. Differentiation amongst of love, sex and sensational touch is normally expected from women. Unfortunately, adolescent stage is the only period where they cannot differentiate at all, for which; there are ample chances to mislead themselves into wrong direction unknowingly. In this context, proper counseling to adolescent girls taking health as core intervention area would one of the major areas of concern. Attitudinal guidance and action in this respect need to be introduced in course syllabus. Introducing health perspective areas could bring in additional values and help them to blend with the mainstream. Simultaneously, negative trend of emotional aspect and decision making process with peer groups and family members change the dimensions of the situation. In other way, addiction to the drugs is normally seen during this stage and it is easiest way to be trapped into the field of intervention. For instance, failure of love, lack of clarity about future plan and perspectives, career confusion and adopting ideologies creates confusion in a larger scenario $\frac{12}{}$.

\section{Traumatic Situation of Adolescent Girls}

It is generally observed that adolescent girls are more prone to consider schools as traumatic hub. A number of stressful factors like demands from the school and the resulting frustration arising by being not able to meet it. Inculcating negative thoughts and feeling towards themselves and others, physical changes of the body structure, attitudinal variance among peer groups are being considered as difficult areas for the adolescent girls. However, it could have been addressed through taking community participatory approach at ground zero. Teacher, parents, students and trained professional or experienced person within the community should come forward to address such issues and contribute constructive ideas. Also, creation of a conducive environment would be one of the appropriate methods for establishing a vibrant society $\frac{13,14}{\text {. }}$

\section{Models in Primary Education System}

Health and education service at educational institutes have assumed prime importance, especially after introduction of Sarva Sikshya Abhiyan (SSA) through Right to Education Act under article 21-A of Indian Constitution. Yes, the step towards infrastructure development at the government level is undoubtedly remarkable. But, the infrastructures at the educational institute level must have to be fully sync with the overall project. Otherwise, hardly any benefit can be derived from the investment. A sanitary infrastructure, without the provision of round the clock water facility cannot be considered as an investment. Rather, it may be treated as an example of poor implementation and ineffective management practices starting from bottom to top level. Looking into need of health and sanitation at school, state management units of Sarva Sikshaya Abhiyan (SSA) and educational service provider authority has developed network based alliance. These agencies basically work on policy formulation and implication of health services at national level. The study found that around $1 / 3^{\text {rd }}$ schools don't have separate toilet 
facility for the adolescent girls. In addition to this, close to $90 \%$ toilet rooms are far from piped line water connection. The correlation value (2.37) of attendance and sanitation facilities in educational institute is strongly being connected towards quality education services. Toilet with piped line water connection has significant contribution of better health and increase of attendance during and post menstrual periods. It is one of the indictor represents in assessing institutional health services within educational premises. In this connection, while discussing with various stake holders, sum total opinions were gathered. The findings suggested that there are few areas which need to be addressed where each educational institute should assess under such parameters through public private partnership mode. These criteria are like 1. Policies on health endorsement, 2. Health education in school syllabus, 3. Smoking and hazardous free environment, 4. Healthier eating, 5. Environment, 6. Wellbeing, 7. Peer community and 8 . Safety and security at school.

However, it is assumed that school environment has enough potential for enabling community participation within school structure and also could sense a bigger idea for creating possible conducive environment. In this approach, not students only get adequate benefits but other people living within the surrounding can access better services also. The idea could be materialized through forming a small group along with specific assigned tasks to perform. The group must have to keep in touch with various stake holders of the community, including students of the respective classes or schools.

\section{Ground Reality of Institutional Health and Hygiene}

The exploratory study was conducted in 10 schools of Khurdha district of Odisha. During the study, the authors inspected the overall situation of existing toilet and drinking water facilities for adolescent girls in the educational institutes. Separate toilets for boys and girls were limited. While there was 1 toilet for 26 boys, for girls the number shot up to 35 . The adolescent girls are more vulnerable and being forced to access such facilities. In other way, condition of boys has almost similar condition but they can use open space which is considered as normal practice in most the Indian culture. In this circumstance, the average number per toilet has to reduce at any cost and provision of round the clock water supply with closed door system needs to be ensured in each institutional set up. The clean- ing of toilet and environment is one of the most important aspects of health and hygiene. To be free from urine infectious diseases; both surrounding environment and toilet must have to be clean and safe for everybody to use.

\section{Model of Institutional Health and Hygiene}

Researchers and people with professional expertise in this field can give valuable input. Audit of the local schools is necessary. Awareness can be spread by conducting programmes. Evaluation of a Partnership Model, forming policies and executing them in the right way is instrumental. A better health and hygiene system can be practiced through consultation within the vicinity of the schools and with exposure visits. Monitoring and gatekeeping by local stakeholders, communities and social workers are vital input to the institutional system.

Apart from external input, schools should put in their own efforts as well. Separate toilets should be constructed with proper pipeline water supply to each toilet. It should be ensured that the drinking water is clean and safe. A working disposal machine is a must. A first aid kit is the basic in the health care field. Awareness can be spread among students regarding hygienic lifestyle.

Table 1. Ground reality

\begin{tabular}{|c|c|}
\hline Indicator & Facts in Number / Percentage \\
\hline \multicolumn{2}{|r|}{ Toilet } \\
\hline Toilet Location & $\begin{array}{l}\text { All toilets are within school } \\
\text { campus }\end{array}$ \\
\hline Separate toilets & $\begin{array}{l}100 \% \text { separate toilets for } \\
\text { adolescent girls }\end{array}$ \\
\hline No. of separate toilets & $\begin{array}{l}\text { For Boys: 1:26 } \\
\text { For Girls: 1:35 }\end{array}$ \\
\hline Toilets open & 1/3rd Schools \\
\hline Water facility to toilet & $\begin{array}{l}90 \% \text { water connectivity system } \\
94 \% \text { unavailability water supply } \\
\text { to toilet }\end{array}$ \\
\hline $\begin{array}{l}\text { Availability of toilet } \\
\text { soaps, hand wash, liquid } \\
\text { etc }\end{array}$ & Not available \\
\hline Toilet doors & $\begin{array}{l}\text { All time locked (Teachers keep } \\
\text { key) }\end{array}$ \\
\hline Cleaning toilets & $\begin{array}{l}\text { All toilets cleaned by the } \\
\text { students } \\
\text { Usually once in a month by } \\
\text { sweeper on call }\end{array}$ \\
\hline
\end{tabular}




\begin{tabular}{|l|l|}
\hline \multicolumn{2}{|c|}{ Drinking water } \\
\hline $\begin{array}{l}\text { Availability of Safe } \\
\text { drinking water source }\end{array}$ & $\begin{array}{l}91.24 \% \text { drinking water machines } \\
\text { are defunct }\end{array}$ \\
\hline $\begin{array}{l}\text { Sources of drinking } \\
\text { water }\end{array}$ & $\begin{array}{l}\text { Tube well - 91\% schools } \\
\text { Well - 5\% schools } \\
\text { Bore well - 4\% }\end{array}$ \\
\hline
\end{tabular}

Source: Field Study in Khurdha District, Odisha

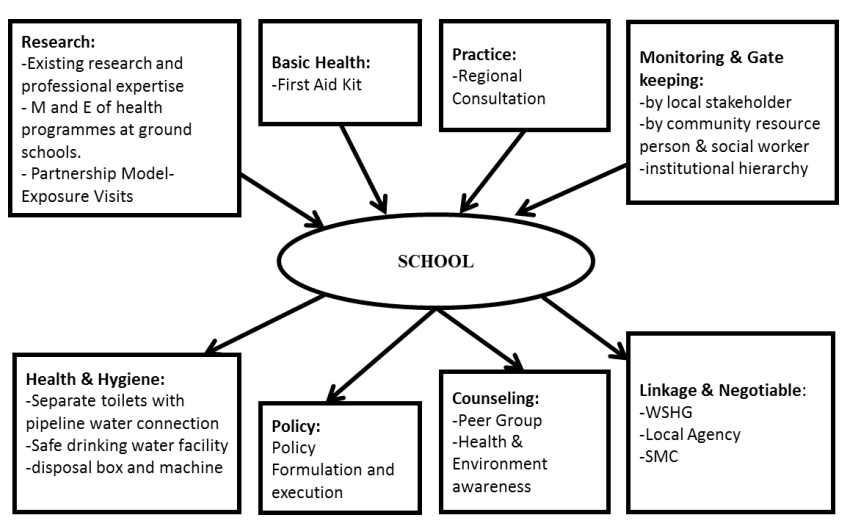

Figure 1. Proposed model.

\section{Conclusion}

The assessment of Institutional health and hygiene is definitely a new area of research and development which could be redesigned at the policy and program level.

During the study, it has been found that for daily cleanliness of children, of kitchen, bathroom, living room and premises of the institution with the support of children health and sanitation committee as well as overall responsibility of staff should come forward and play proactive role. It could also be enforced through proper strategic operational management process. Besides this the stakeholders at management and sub-management should involve staffs and children to conduct regular awareness programs on different diseases, health wall, and installation of dustbin in various places of the campus. The National Rural Health Mission (NRHM) initiative towards assignment of different NGOs in different locality to look after day to day health affair is really appreciable. Update of first aid medicine, health care of each child as well a health check-up for first timer to the institution must be given on priority. However, the situation could be managed effectively through interdepartmental coordination, proper program monitoring and development of self monitoring regulatory mechanisms.

\section{Reference}

1. Aggleton P, Rivers K, Chase E, Downie A, Mulvihill C, Sinkler P, Tyrer P, Warwick I. Learning lessons: A report on two research studies conducted to inform the National Healthy School Standard (NHSS), DH/DfEE, Department of Health and the Department for Education and Employment, Institute of Education, University of London, 27- 28 Woburn Square, London WC1H0AA; 1999. p. 20-8.

2. Allensworth $\mathrm{D}$. The research base for innovative practices in school health education at the secondary level. Journal of School Health. 1994; 64(5):180-7. PMid: 8078311. Crossref.

3. Atkinson P. The Symbolic Significance of Health Foods. Turner, P. Ed. London: Nutrition and Lifestyles, Journal of Applied Science Publications; 1980.

4. Denman S. Health promoting schools in England - A way forward in development. Journal of Public Health Medicine. 1999; 21(2):215-20. PMid: 10432253. Crossref.

5. Ivan Y, Williams R. The salt of the earth: Ideas linking diet, exercise and virtue among elderly Aberdonians. Social Class Attitudes to Diet and Health. Journal of Nutrition and Food Science. 1985 Sep-Oct; 96:15.

6. Jamison J. Ashby P. Hamilton K, Lewis G, MacDonald A, Saunders L. The health promoting school. London: Final Report of the ENHPS Evaluation Project in England, Health Education Authority; 1998. p. 67-71.

7. McBride N. Cameron I, Midford R, James R. Facilitating health promotion in Western Australian schools: Key factors for success. Health Promotion Journal of Australia. 1995; 5(1):11-6.

8. Moon A, Mullee M, Thompson R, Speller V, Roderick P. Helping schools to become health promoting environments: An evaluation of the Wessex Healthy Schools Award. Journal of Health Promotion International. 1999; 14(2):111-22. Crossref.

9. Murcott A. The Sociology of Food and Eating. Aldershot, Hampshire, England: Gower Publishing; 1983. p. 106-16.

10. Murray DD. Blueprint for Health. London: George Allen and Unwin; 1973. p. 19.

11. Swain J. Life skills education for youth. New Delhi: Central Social Welfare Board; 2011 Jan; 57:5-10.

12. Timothy G, Moore M, McDonald L, Carlon K. Early childhood development and the social determinants of health inequities. Health Promotion International. 2015 Sep; 30(2):ii102-15. Crossref.

13. Warwick I. et. Al. Evaluating healthy schools: Perceptions of impact among school based respondents. Health Education Research. 2005; 20(6):697-708.

14. Healthy Schools, healthy Children? The contribution of education to pupils health and wellbeing; 2017. http://dera.ioe.ac.uk/6132/1/Healthy_ schools\%2C_healthy_children_The_contribution _of_education_to_pupils\%27_health_and_well-being_\%28PDF_ format $\% 29 . p d f$ 